\title{
Article \\ Infrared Radiation Favorably Influences the Quality Characteristics of Key Lime Juice
}

\author{
Ammar B. Altemimi ${ }^{1, *}$, Asaad R. S. Al-Hilphy ${ }^{1}\left(\mathbb{D}\right.$, Tarek Gamal Abedelmaksoud ${ }^{2}$, Salam A. Aboud ${ }^{1}$, \\ Laxmikant S. Badwaik ${ }^{3}$ (D) , Lakshmanan $G^{4}$, Shaba Noore ${ }^{5}$ and Anubhav Pratap-Singh ${ }^{6, *(D)}$ \\ 1 Department of Food Science, College of Agriculture, University of Al-Basrah, Basrah 61004, Iraq; \\ aalhilphy@yahoo.co.uk (A.R.S.A.-H.); salamalmiyahi@gmail.com (S.A.A.) \\ 2 Food Science Department, Faculty of Agriculture, Cairo University, Giza 12613, Egypt; \\ tareekgamal_88@agr.cu.edu.eg \\ 3 Department of Food Engineering and Technology, School of Engineering, Tezpur University, \\ Napaam 784028, India; laxmikantbadwaik@gmail.com \\ 4 Department of Biotechnology, Bharath Institute of Higher Education and Research, \\ Selaiyur, Chennai 600073, India; lakshmanang261988@gmail.com \\ 5 School of Biosystems and Food Engineering, University College Dublin, D04V1W8 Dublin 4, Ireland; \\ shaba.noore@ucdconnect.ie \\ 6 Food, Nutrition \& Health Program, Faculty of Land and Food Systems, The University of British Columbia, \\ Vancouver, BC V6T 1Z4, Canada \\ * Correspondence: ammar.ramddan@uobasrah.edu.iq (A.B.A.); anubhav.singh@ubc.ca (A.P.-S.)
}

Citation: Altemimi, A.B.; Al-Hilphy, A.R.S.; Abedelmaksoud, T.G.; Aboud, S.A.; Badwaik, L.S.; G, L.; Noore, S.; Pratap-Singh, A. Infrared Radiation Favorably Influences the Quality Characteristics of Key Lime Juice. Appl. Sci. 2021, 11, 2842. https:// doi.org/10.3390/app11062842

Academic Editor: Dong-Un Lee

Received: 2 March 2021

Accepted: 17 March 2021

Published: 22 March 2021

Publisher's Note: MDPI stays neutral with regard to jurisdictional claims in published maps and institutional affiliations.

Copyright: (c) 2021 by the authors. Licensee MDPI, Basel, Switzerland. This article is an open access article distributed under the terms and conditions of the Creative Commons Attribution (CC BY) license (https:// creativecommons.org/licenses/by/ $4.0 /)$.

\begin{abstract}
The effect of infrared radiation (IR) on thephysicochemical characteristics, pectin methylesterase activity (PME), hydroxymethylfurfural (HMF) content, microbiological activity, color, and sensory aspects on black lime juice was studied. IR was compared to conventional thermal heating $(\mathrm{CTH})$ in batch infrared extraction pasteurizer, designed to allow both infrared and conventional heating. IR resulted in a reduction in $\mathrm{pH}$ and Brix values and a mild increase in titratable acidity, as compared to $\mathrm{CTH}$ and control. After 60 days at $5{ }^{\circ} \mathrm{C}$, the ascorbic acid percentage was decreased by $24.90 \%, 29.75 \%$, and $58.31 \%$ in the control, IR and CTH, respectively. The total amount of phenols in juice treated with IR was higher as compared to CTH and control, while there was a significant decrease in the antioxidant activity. The statistical analysis reflected significantly low $(p<0.05)$ activity of PME for IR samples as compared to CTH and control. The amount of Hydroxymethylfurfural (HMF) in all juice samples steadily increased during the storage at $5{ }^{\circ} \mathrm{C}$ in 60 days. The microbial content of control was $3.85 \log \mathrm{cfu} / \mathrm{mL}$ after 60 days at $5{ }^{\circ} \mathrm{C}$, while it was $2.1 \log \mathrm{cfu} / \mathrm{mL}$ for IR which reflected a significant difference between the IR, CTH, and control samples. Additionally, color and sensory analysis of IR treated sample when compared to control, reflected similar attributes. Overall, IR was found to be an excellent substitute for the preservation of black lime juice as a rapid pasteurization technique with less heat exposure; wherein the nutrition and health benefits of the juice could be maintained for a minimum period of 60 days.
\end{abstract}

Keywords: infrared radiation; lime; juice; hydroxymethylfurfural; pectin methylesterase

\section{Introduction}

Tropical and sub-tropical geographical areas of the world are covered with a variety of citrus cultivation. Their exquisite flavor and delightful nutritional benefits have made them an excellent fruit crop around the globe [1]. Citrus aurantifolia commonly known as key lime is broadly utilized as a flavoring agent in various cuisine. It is also consumed as a beverage around the world. It consists of medicinal attributes including anti-diabetic, anti-fungal, anti-bacterial, and anti-hypertensive which can protect the human body from several chronic diseases such as cancer and cardiovascular diseases. Besides, it also helps in boosting up the immunity level of the body by providing a richness of antioxidants, mainly ascorbic acid (AA) flavonoids, phenolic acid, carotenoids, alkaloids, and coumarins [2]. 
The major source of vitamins in the human body is by consumption of fruits and vegetables $(>90 \%)$ as the human body is incapable of synthesizing these nutrients [3].

During the processing of such citrus fruits and their products, the key challenge faced by the food industries is the preservation of the nutritional attributes of the fresh produce with extended shelf life. However, most of the essential nutrients are reduced due to various physical and chemical changes during processing including high temperature, reduced relative humidity, and enzymatic reactions. Before purchasing processed juice from the market, the first and foremost thing that a consumer notices is its appearance. A nonenzymatic reaction takes place when sugars in the juice react with ascorbic acid and amino acids, which leads to degradation in taste, color, and overall acceptability of the juice due to the formation of a brown pigment. When subjected to thermal processing, the problem is exacerbated leading to alterations in the appearance of the juice. The organoleptic and color profile of the citrus juices depends on two main factors, i.e., the presence of cloudiness in the juice and its turbidity, which are stabilized in citrus juices by pectin [4]. Enzyme accountable for the de-esterification of methoxylated pectin and development of insoluble calcium pectate with lowering of juice viscosity is Pectin Methylesterase (PME), popularly called pectinase and pectinesterase. To inactivate this PME enzyme and other microbial activities, juices undergo thermal treatment, which invariably causes loss of nutritional value and produces undesirable flavors in the juice product, especially at temperatures higher than $80^{\circ} \mathrm{C}[5,6]$. Thermal processing also decreases nutritional content, especially in the case of citrus fruits, as ascorbic acid is extremely sensitive to heat [3,7]. Several juice-processing experts have studied the quality changes in lime juice during thermal processing, and thus it is extremely required to find out the solution for this problem [8-10]. Recent advances in thermal processing have resulted in the emergence of various methods to minimize process times for juice processing through rotary [11], reciprocating [12], and controlled agitation processes [13]. Other works have focused on natural acidification and incorporation of essential oil components for organic preservation [14], still, a need has been felt to explore alternate processing techniques for minimizing quality changes in juice processing.

Interestingly, in past few years, researchers have found an alternate for this problem by introducing Infrared Radiation (IR) between 0.5 to $100 \mu \mathrm{m}$ wavelengths for the preservation of juices especially citrus juice. The merits of infrared application include rapid heating system, straight and even diffusion of heat into the liquid sample. In addition to this, by this new method of processing the nutrient content of the juices is preserved [15]. Commonly, infrared is divided into three regions, namely the near-infrared $(0.78-1.4 \mu \mathrm{m})$, mid-infrared $(1.4-3.0 \mu \mathrm{m})$ and far-infrared (3.0-1000 $\mu \mathrm{m})$ [14], with far-infrared commonly employed in food processing industries [15]. During this process, the surface of the food comes in contact with the infrared and gets heated up, with the heat then gradually diffusing into the inside layers of the product. The time period required to dehydrate apple slices was reduced by $50 \%$ by using near-infrared [16]. Moreover, Tan et al. [17] report reflected positive results as infrared managed to reduce the color change significantly. Whereas another report by Boudhrioua et al. [18] indicates that in the case of olive leaves, the total phenol content was amplified in contrast to fresh leaves. Although, there are a large number of advantages of infrared application in the food processing industry, yet it has not been used broadly to preserve the juices to retain their natural quality along with extended shelf life. Therefore, this study aims to investigate the application of infrared radiation on key lime juice by monitoring variations in its physical, chemical, enzymatic, and microbiological characteristics in comparison with the conventional thermal preservation method.

\section{Materials and Methods}

\subsection{Chemicals, Solvent, and Black Lime Procurement}

Black Lime (BL; Citrus aurantifolia) was procured from a local market, Basrah, Iraq. All chemicals and reagents were of analytical grade. Sodium hydroxide $(\mathrm{NaOH})$; potassium iodate $\left(\mathrm{KIO}_{3}\right)$; potassium iodide $(\mathrm{KI})$; sulfuric acid $\left(\mathrm{H}_{2} \mathrm{SO}_{4}\right)$; Folin-Ciocalteu reagent; sodium 
chloride (NaCl); gallic acid; 1, 1-diphenyl 2-picrylhydrazyl (DPPH) radical; methanol; pectin; Trichloroacetic acid TCA were obtained from was obtained from Sigma, Germany and Thiobarbituric acid was obtained from Carlo Erba, Italy. Peptone water, MacConkey agar, and potato dextrose agar were obtained from Himedia, Mumbai, India.

\subsection{Black Lime Juice Processing}

Initially, key lime was dried at ambient temperature and preserved at room temperature for further experimental purposes. On the day of experimentation, $500 \mathrm{~g}$ of black lime was crushed into a fine powder and allowed to pass through 40-mesh. The sieved black lime powder along with sugar $(1550 \mathrm{~g})$ and water $(10,000 \mathrm{~mL})$ was mixed in the reservoir of a juice pasteurizer equipped with infrared and conventional heating systems (Figure 1) [19]. The temperature and emission of infrared radiation (wavelength $6 \mu \mathrm{m}$ ) were monitored using the control panel of the reservoir. The black lime juice was mixed by the continuous stirring system that allowed the equal distribution of heat. Further, the mixture is passed through the filter ( $25 \mu \mathrm{m}$ screen) and poured out of the reservoir. Next, another batch of black lime juice was processed using conventional heating using an electric heater at $90{ }^{\circ} \mathrm{C}$ for $15 \mathrm{~min}$. Processed juice was kept at $5{ }^{\circ} \mathrm{C}$ for further experiments. IR treated juice at a single temperature $\left(62.2^{\circ} \mathrm{C}\right)$ and power setting $(700 \mathrm{~W})$ were compared with conventional heating and control juice.

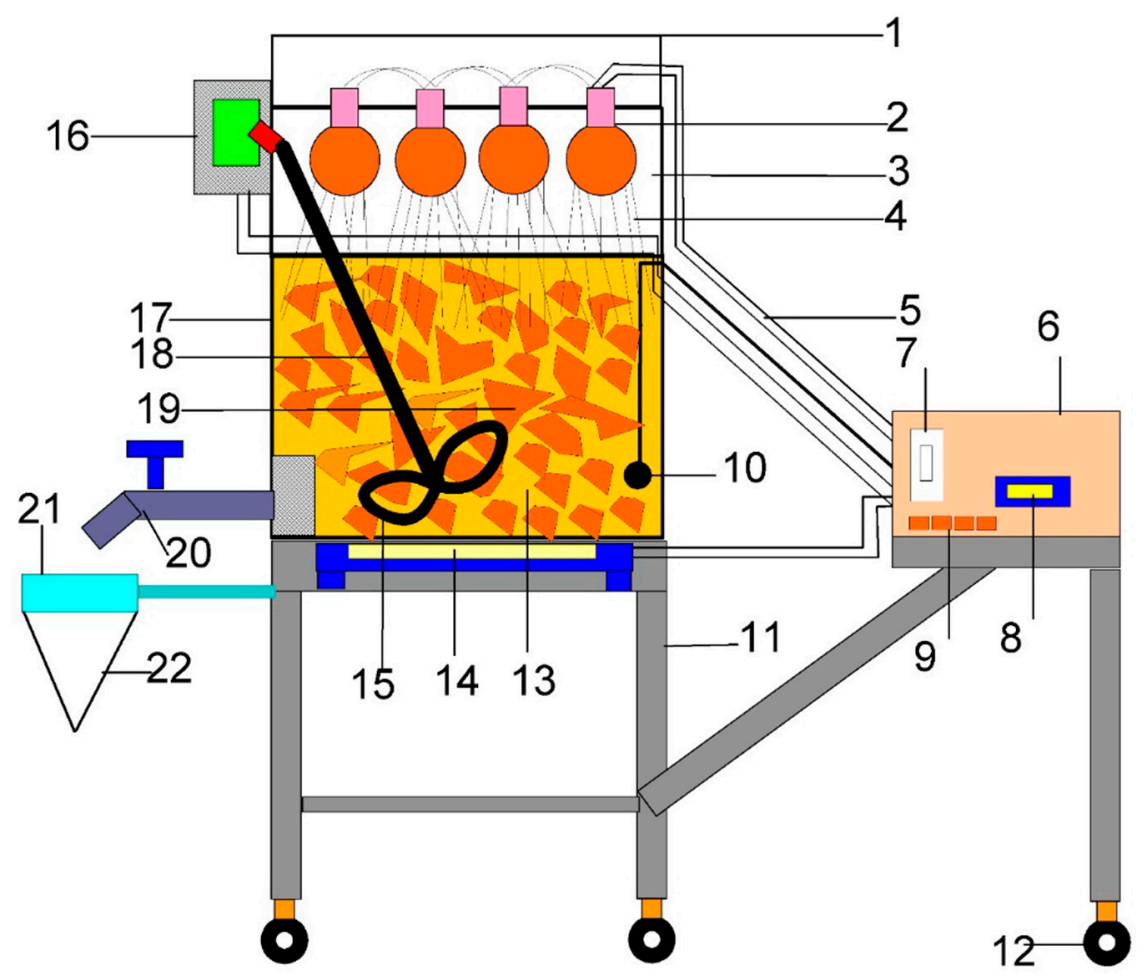

Figure 1. Schematic diagram of batch infrared extraction pasteurizer (BIREP) consisting of: (1) external cover; (2) infrared lamps; (3) internal cover; (4) infrared radiation; (5) wires; (6) control panel; (7) switch; (8) digital temperature gauge; (9) operation switches; (10) thermocouple; (11) chassis; (12) tire; (13) water; (14) electric heater; (15) mixer; (16) electric motor; (17) reservoir; (18) shaft; (19) pieces of dried Basrah lime; (20) tap; (21) screen; (22) funnel. Adopted with permission from Aboud et al. [19]

\subsection{Physicochemical Analysis}

\subsubsection{Total Soluble Solids (Brix) and $\mathrm{pH}$ Value}

Total soluble solids (TSS) were estimated using a refractometer (Bellingham, UK). A drop of black lime juice was poured onto the prism of the refractometer and conversion factors were applied to indicate the Brix value. Further, about $10 \mathrm{~mL}$ of black lime juice 
was taken in a beaker and placed on a magnetic stirrer to test the $\mathrm{pH}$ value at $25^{\circ} \mathrm{C}$ using a digital $\mathrm{pH}$ meter.

\subsubsection{Titratable Acidity (TA)}

To estimate the TA of black lime juice a revised procedure from Bhat et al. [20] was conducted. About $10 \mathrm{~mL}$ of black lime juice was mixed with $200 \mathrm{~mL}$ of distilled water which was further subjected to titration till the endpoint of phenolphthalein (8.2 \pm 0.1$)$ by $0.1 \mathrm{~N} \mathrm{NaOH}$. The reduced volume of $\mathrm{NaOH}$ was noted and TA \% was calculated based on the formula given below

$$
\mathrm{TA}(\% \text { citric acid })=\frac{\mathrm{mL} \text { of } \mathrm{NaOH}(0.1 \mathrm{~N}) \times 0.067 \times 100}{10}
$$

\subsubsection{Ascorbic Acid (AA) Content}

A revised procedure of iodine titration by Kashyap [21] and Jafari [22] was employed to estimate the ascorbic acid content of black lime juice. Initially, $200 \mathrm{~mL}$ of distilled water was taken to dissolve $268 \mathrm{~g}$ of $\mathrm{KIO}_{3}$ and $5 \mathrm{~g}$ of $\mathrm{KI}$. Further, $30 \mathrm{~mL}$ of $3 \mathrm{M} \mathrm{H}_{2} \mathrm{SO}_{4}$ was added to the solution and made up to $500 \mathrm{~mL}$ using distilled water. Besides, $1 \%(w / v)$ of the starch solution was also prepared to be used as an indicator. Now to estimate Ascorbic acid, $20 \mathrm{~mL}$ of black lime juice was diluted by $150 \mathrm{~mL}$ of distilled water along with 10 drops of starch solution. The solution was subjected to iodine titration till its color changed to clear dark blue. The change in the volume of iodine solution was noted and ascorbic acid $\%$ was calculated based on the formula given below.

$$
\text { Ascorbic acid content }(\mathrm{mg} / 100 \mathrm{~mL} \text { juice })=0.88 \times \text { iodine solution }(\mathrm{mL})
$$

\subsubsection{Total Phenolic Content (TPC)}

Total phenolics of the black lime juice were estimated by following Folin-Ciocalteu procedure. Initially, a mixture of $0.5 \mathrm{~mL}$ black lime juice, $1 \mathrm{~mL}$ of $10 \%(w / v)$ Folin-Ciocalteu reagent, and $2 \mathrm{~mL} \mathrm{NaCl} 20 \%(w / v)$ was prepared by thoroughly mixing it for $6 \mathrm{~min}$. The mixture was allowed to incubate for $60 \mathrm{~min}$ at $30{ }^{\circ} \mathrm{C}$. At $760 \mathrm{~nm}$ the absorbance was recorded by the spectrophotometer (Jenway, Model 6305, Staffordshire, UK). To prepare the calibration curve gallic acid was used and the result was expressed in $\mathrm{mg}$ gallic acid equivalents /100 g dry weight [23-26].

\subsubsection{Antioxidant Activity}

To determine the antioxidant activity of the black lime juice a revised protocol of Wiktor et al. [26] and Sethi [27] was conducted. Initially, $25 \mathrm{mg}$ of DPPH radical was mixed with methanol $50 \%(v / v)$ to prepare a DPPH solution. About, $0.1 \mathrm{~mL}$ of black lime juice was mixed in $3.9 \mathrm{~mL}$ of DPPH solution and kept under incubation for $25 \mathrm{~min}$ at ambient temperature. At $517 \mathrm{~nm}$ the absorbance was recorded by the spectrophotometer (Jenway, Model 6305, UK). The antioxidant activity (\%) was calculated using the given formula.

$$
\text { Antioxidant activity }(\%)=\frac{\mathrm{A}_{\mathrm{c}}-\mathrm{A}_{\mathrm{j}}}{\mathrm{A}_{\mathrm{c}}} \times 100
$$

where $A_{c}$ is the control absorbance and $A_{j}$ is black lime juice absorbance.

\subsection{Pectinmethylesterase (PME)}

Kimball [28] reported a protocol that was followed with some minor changes to estimate PME. Initially, a mixture of $\mathrm{NaCl}$ and pectin (15.3 $\mathrm{g}$ and $10 \mathrm{~g}$ respectively) was dissolved in distilled water to prepare a $1 \%$ standard solution of pectin-salt. Besides, $\mathrm{NaOH}$ solution of $2 \mathrm{~N}$ and $0.05 \mathrm{~N}$ was prepared and kept for further utilization. To estimate PME, $10 \mathrm{~mL}$ of black lime juice was mixed with $40 \mathrm{~mL}$ of pectin-salt solution in a $100 \mathrm{~mL}$ beaker. Now the beaker was placed inside another beaker of $250 \mathrm{~mL}$ filled with water. Further, 
both the beakers were subjected to a magnetic stirrer with the temperature set at $30^{\circ} \mathrm{C}$, after some time when the desired temperature was attained, few drops of $\mathrm{NaOH}(2 \mathrm{~N})$ solution was added to $100 \mathrm{~mL}$ beaker to change the $\mathrm{pH}$ of the solution to 7 followed by addition of $\mathrm{NaOH}(0.05 \mathrm{~N})$ to maintain the $\mathrm{pH}$ in 7.6-7.8 range. Further, to calculate the activity of PME, $0.1 \mathrm{~mL}$ of $\mathrm{NaOH}(0.05 \mathrm{~N})$ was poured into the solution and the time was recorded for the solution to attain the same $\mathrm{pH}$ range. The equation applied to measure the PME is given below:

$$
\mathrm{PME}(\text { unit } / \mathrm{mL})=\frac{\mathrm{NaOH}(0.05 \mathrm{~N}) * 0.1 \mathrm{~mL} \mathrm{NaOH}(0.05 \mathrm{~N})}{10 \mathrm{~mL} \text { of sample } * \text { time }(\text { minute })}
$$

\subsection{Hydroxymethyl Furfural (HMF)}

To estimate HMF of black lime juice a revised procedure of Cohen et al. [29] was followed. Initially, a mixture of infrared treated samples and Ethyl alcohol $(10 \mathrm{~mL}$ and $5 \mathrm{~mL}$ of $95 \%$ respectively) was centrifuged for $15 \mathrm{~min}$ at $1000 \mathrm{RPM}$. About, $2 \mathrm{~mL}$ of supernatant was collected and mixed with $2 \mathrm{~mL}$ each of $0.025 \mathrm{M}$ thiobarbituric acid and $12 \% \mathrm{w} / \mathrm{w}$ trichloroacetic acid. The mixture tube was subjected to a water bath for $50 \mathrm{~min}$ to attain temperature up to $40 \pm 0.5^{\circ} \mathrm{C}$. The amount of HMF present in black lime juice was measured using a calibration curve (Aldrich, Darmstadt, Germany).

\subsection{Microbiological Analysis}

Microbial analysis was carried out using serial dilution (10-1 to 10-3) method where a sterilized glass tube was filled with a mixture of $9 \mathrm{~mL}$ of peptone water and $1 \mathrm{~mL}$ black lime juice to estimate total plate counts, coliform bacteria, yeast, and mold. Further, the serial dilution was done and $1 \mathrm{~mL}$ from each test tube was poured on agar plates. At $35^{\circ} \mathrm{C}$ for 24-28 $\mathrm{h}$ agar plates were incubated which were then subjected for TPC. MacConkey agar was used for the estimation of coliform bacteria while in the case of yeast and mold potato dextrose agar was utilized with the incubation period of 3 days at $37^{\circ} \mathrm{C}$. The results were calculated based on $\log \mathrm{cfu} / \mathrm{mL}$ of black lime juice for the shelf life of 0 to 60 days [30,31].

\subsection{Determination of Color}

Color values of black lime juice were carried out using a 6-megapixel digital camera (Android \& PC Endoscope, type-C, Shenzhen, China). The image was analyzed using software called ImageJ and the standard value of the color parameter was generated by the conversion of its mean value as reported by Yam and Papadakis [32]

$$
\begin{aligned}
\mathrm{L}^{*} & =\frac{\mathrm{L}}{255} \times 100 \\
\mathrm{a}^{*} & =\frac{240 \mathrm{a}}{255}-120 \\
\mathrm{~b}^{*} & =\frac{240 \mathrm{~b}}{255}-120
\end{aligned}
$$

where, $\mathrm{L}=$ lightness, $\mathrm{a}=$ redness /greenness, $\mathrm{b}=$ yellowness/blueness, $\mathrm{L}^{*}, \mathrm{a}^{*}$ and $\mathrm{b}^{*}$ are corrected values.

\subsection{Sensory Analysis}

A sensory assessment of black lime juice was carried out by the panel of 10 trained judges including $70 \%$ male and 30\% female with two age groups at $60 \%$ (28-41 years) and $40 \%$ (43-59 years). Judges were asked to assess the appearance, aroma, taste, and overall acceptability of black lime juice on a scorecard of 1 to 4 . There were three samples for assessment including black lime juice treated with infrared, conventional, and fresh black lime juice [33]. 


\subsection{Statistical Methods}

The entire experiments were performed in triplicates, and data are presented as mean \pm standard error (SE). All the analyses were calculated using the Statistical Package of Social Sciences (SPSS) software package version 16.0. Data were assessed for significant difference employing one-way ANOVA and were considered to be statistically significant at $p<0.05$.

\section{Results and Discussion}

\subsection{Physiochemical Content of Stored Juice Samples}

Figure 2 shows the $\mathrm{pH}$, acidity, and Brix values of the infrared treated juice samples and the thermally treated samples (conventional) and the control sample respectively during storage for 60 days at a temperature of $5{ }^{\circ} \mathrm{C}$. $\mathrm{pH}$ of the product plays an important role in the safety, quality and nutritional bioavailability of the product [34]. It was noticed through the results that there was a decrease in the $\mathrm{pH}$ values with an increase in acidity of the infrared treated juice samples, the thermally treated samples (conventional), and the control sample. These results were consistent with the findings of Ziena [35], as the results indicated a decrease in the $\mathrm{pH}$ values with an increase in the acidity during the storage process.
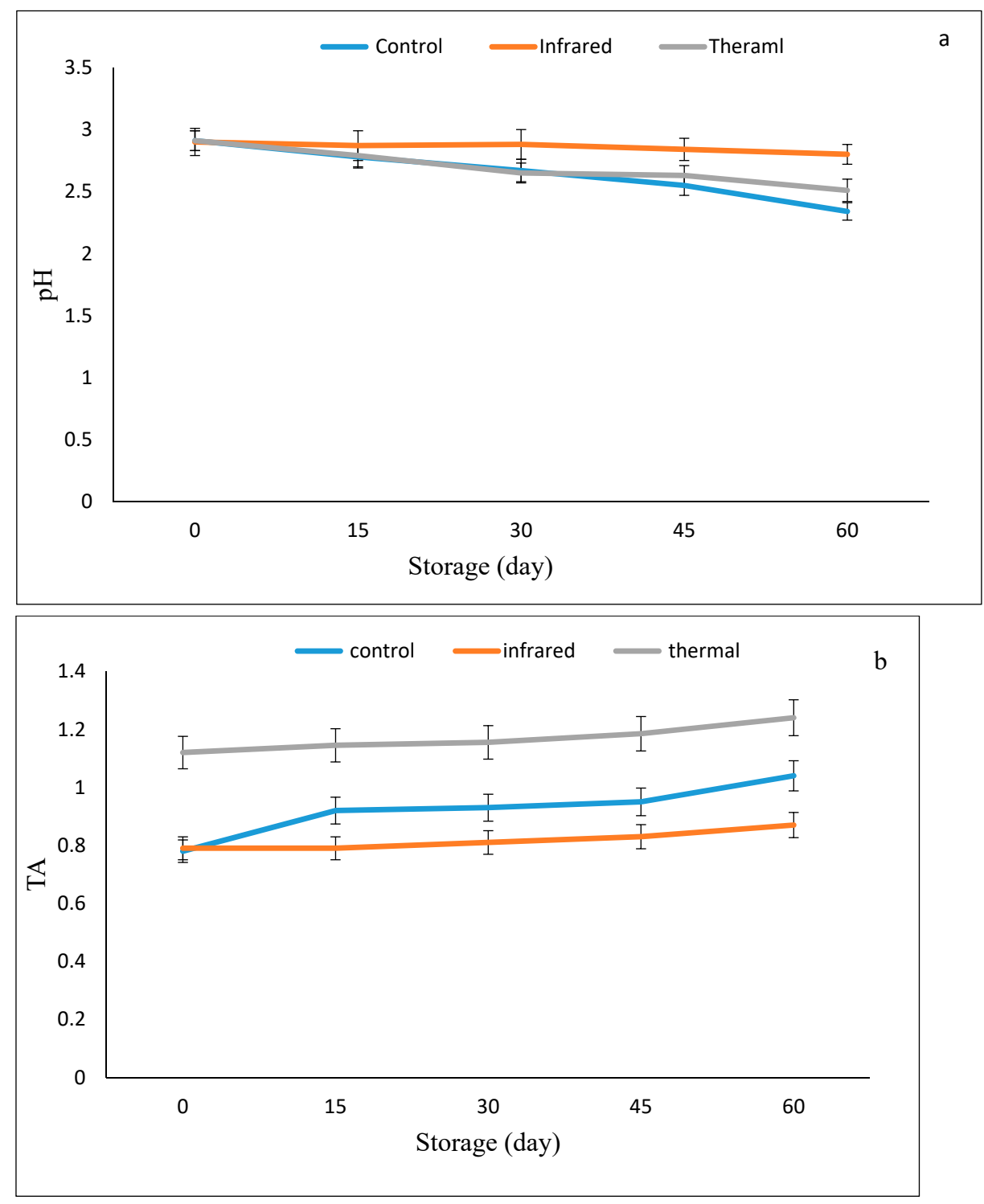

Figure 2. Cont. 


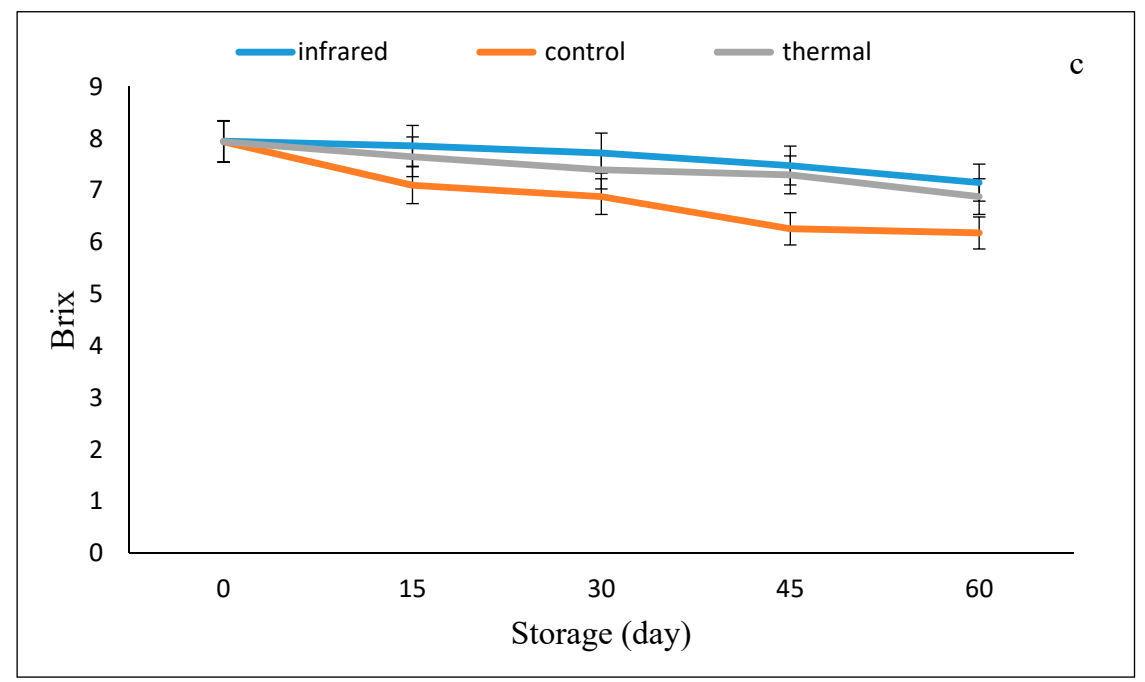

Figure 2. (a) The $\mathrm{pH}$, (b) titratable acidity (TA), and (c) Brix (solids) of the infrared treated juice samples, the thermally treated samples (conventional), and the control sample during storage for 60 days at a temperature of $5{ }^{\circ} \mathrm{C}$.

The results also indicated a decrease in the Brix values of the infrared treated juice samples and the thermal samples (conventional) and the control sample. The results obtained were in agreement with Kaddumukasa et al. [36] who indicated that the decrease was likely due to microbial activities that led to the conversion of sugars in the samples into organic acids and thus caused a decrease in the $\mathrm{pH}$, Brix values and the reduction of the shelf life of the product. The results of the statistical analysis indicated that there were significant differences between the samples of juice treated with infrared radiation compared to the control samples and the samples of thermal (conventional) for each of the values of $\mathrm{pH}$, acidity, and Brix. The results of the statistical analysis indicated that there was a significant difference $(p<0.05)$ between samples thermal samples (conventional) and the control sample for $\mathrm{pH}$, acidity, and Brix values.

\subsection{Determination of Ascorbic Acid}

The results showed in Figure $3 \mathrm{a}$ a decrease in the amount of ascorbic acid when stored for 60 days at a temperature of $5{ }^{\circ} \mathrm{C}$, as the percentage of decrease was $24.90 \%, 29.75 \%$, and $58.31 \%$ in the control sample, the infrared treated juice samples, and the thermal samples (conventional), respectively. These results were consistent with the findings of Mohamed et al. [37] who indicated the inability to retain a higher amount of ascorbic acid in fruit juice during storage depending on storage conditions such as temperature, oxygen, and light. The results of the statistical analysis indicated that there were significant differences between samples of juice treated with infrared radiation compared to samples of control and thermal samples (conventional), as the results showed that the amount of ascorbic acid in samples of fresh juice was higher compared to the infrared treated juice samples and the thermally treated samples (conventional). The results of the statistical analysis also indicated that there was a significant difference $(p<0.05)$ between the control sample and thermal treated samples (conventional). This is confirmed by the results obtained by Torres et al. [38] which indicates that the use of moderate heat treatment during the manufacturing process of juices be able to reduce the loss in the amount of ascorbic acid because it is characterized by being an unstable compound. 

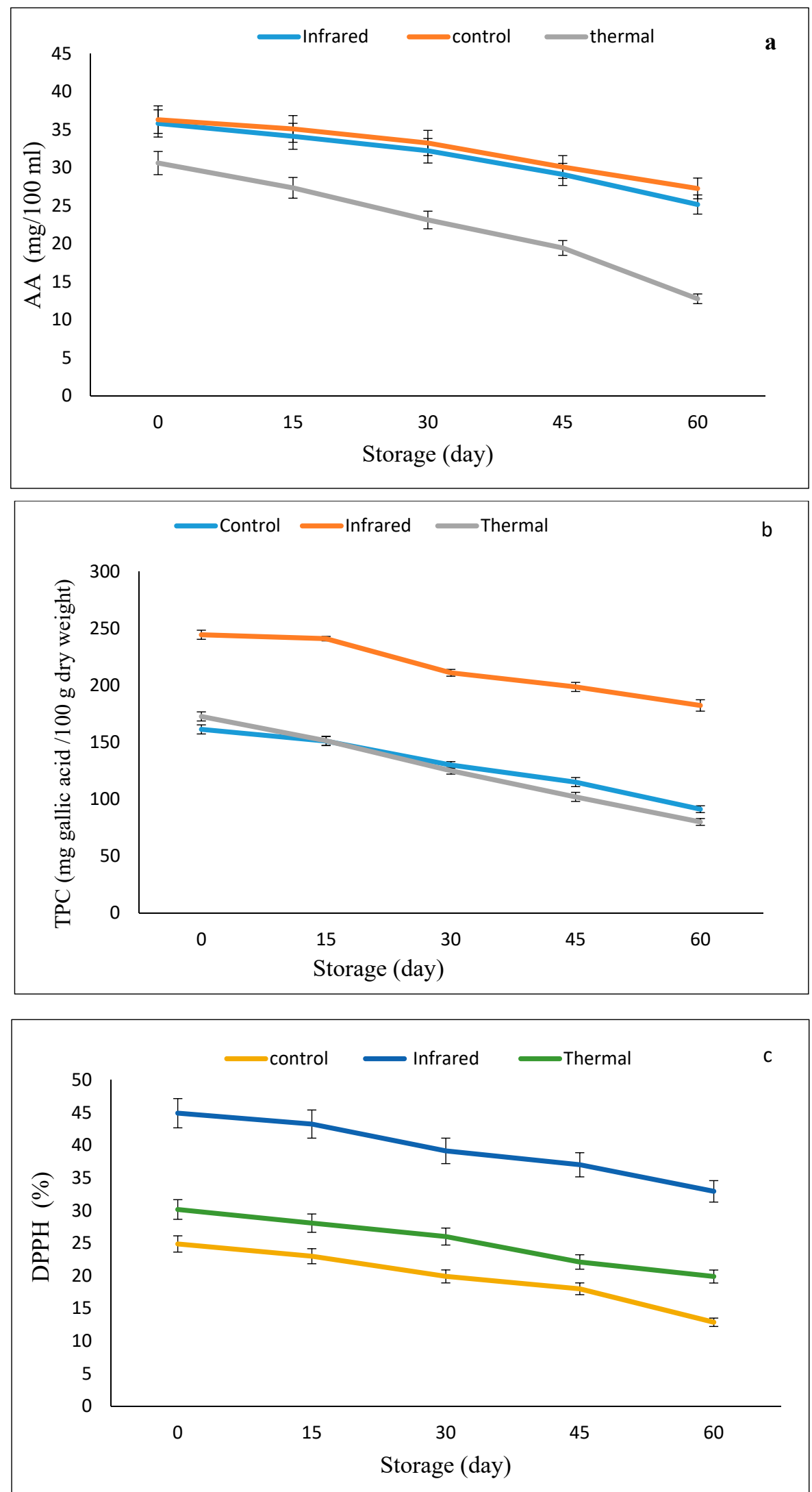

Figure 3. The (a) ascorbic acid (b) total phenolic content (TPC), and (c) antioxidant activity (DPPH \% inhibition) of the infrared treated juice samples, the thermally treated samples (conventional), and the control sample during storage for 60 days at a temperature of $5{ }^{\circ} \mathrm{C}$. 


\subsection{Determination of Total Phenolic Content}

Figure $3 \mathrm{~b}$ shows that the total phenolic content of the control samples for key lime juice decreased significantly $(p<0.05)$ during the advancement of the storage period for 60 days when preservation at a temperature of $5{ }^{\circ} \mathrm{C}$. The results obtained agree with Doroud et al. [39] who indicated a significant decrease in the total phenolic content when fresh lemon juice was stored for 45 days. Several researchers found that the reason for the decrease in the total amount of phenolic is mainly due to the oxidation of the active compounds and the polymerization of proteins [40]. However, the results did not agree with what was indicated by Castro-Lopez et al. [41], who mentioned that some compounds could form and interact with the Folin reagent, which was considered an imprecise detector that could interact with many compounds and thus the amount of phenolic compounds in the juice increased and interfered with the actual amount of total phenols. The results also indicated that there was a significant decrease in the total phenolic content of the thermally treated juice and the use of infrared radiation during storage periods when preservation at a temperature of $5{ }^{\circ} \mathrm{C}$.

The results of the statistical analysis indicated that there were significant differences between the samples of juice treated with infrared radiation compared to the control samples and the thermally treated samples, as the results showed that the total amount of phenols in the juice treated with infrared radiation was higher compared to the control sample and the thermally treated samples. There was a slight but significant difference $(p<0.05)$ between the thermally treated samples and the control sample. The results are in agreement with the findings of Vieira et al. [42], who indicated that there was a slight difference in the heat-treated orange juice samples with the control sample stored for 36 days.

\subsection{Determination of Antioxidant Activity}

Figure $3 c$ showed that the antioxidant activity of the control samples of the juice decreased significantly $(p<0.05)$ when stored at $5{ }^{\circ} \mathrm{C}$ for 60 days. The percentage of decrease in antioxidant activity was $48.25 \%, 34.04 \%$, and $26.66 \%$ for the control sample, thermal treatment, and infrared treated samples, respectively. The results were consistent with Saci et al. [43] who found a decrease in the antioxidant efficacy of fresh carrot juice samples and fresh mango juice upon storage for 90 days at temperatures of $25^{\circ} \mathrm{C}$ and $35^{\circ} \mathrm{C}$, while previous studies indicated a slight decrease in the antioxidant activity of $5.49 \%$ in fresh apple juice stored at a temperature of $30^{\circ} \mathrm{C}$ for a period of 180 days.

The results of the statistical analysis showed that there were significant differences between the juice samples treated with infrared radiation compared to the control samples and the thermally treated samples, as the results showed that the antioxidant activity in the juice samples treated with infrared radiation was higher compared to the control sample and the thermally treated samples. The results agreed with the findings of Lee et al. [44] who indicated the effective aspects of infrared radiation in increasing the percentage of antioxidant compounds. The results of the statistical analysis also indicated that there was a significant difference $(p<0.05)$ between the thermally treated samples and the control sample. The reason for the decrease in the antioxidant activity is due to the presence of a positive correlation between the antioxidant activity and the total amount of phenols. Phenolic compounds play a role significant in inhibiting free radical action and thus increasing antioxidant activity [45].

\subsection{Determination of Pectinmethylesterase Activity (PME)}

The efficacy of PME for fresh lime juice was 0.0120 units $/ \mathrm{mL}$, as the researchers indicated the main role that the residual activity of this enzyme plays in the stability of the citrus juice [46]. Figure 4a shows that the activity of the PME for control samples was increased during the 60 -day storage period at a temperature of $5{ }^{\circ} \mathrm{C}$, as the PME activity ranged from ( 0.0120 to 0.0972$)$ units $/ \mathrm{mL}$. However, the obtained results showed the stability of the PME activity for the thermally treated samples for 15 days of storage 
at a temperature of $5{ }^{\circ} \mathrm{C}$, after which the PME activity was significantly increased from the period 15 to 60 days of storage and at the same temperature. These results were in agreement with the findings of Esteve et al. [47] and Agcam et al. [48] who indicated an increase in the activity of the PME between the third and sixth week due to the emergence of isomers that are characterized by their resistance to high temperatures, and thus an increase in the activity of the PME from 0 to $33 \%$ of the overall effectiveness of the PME.
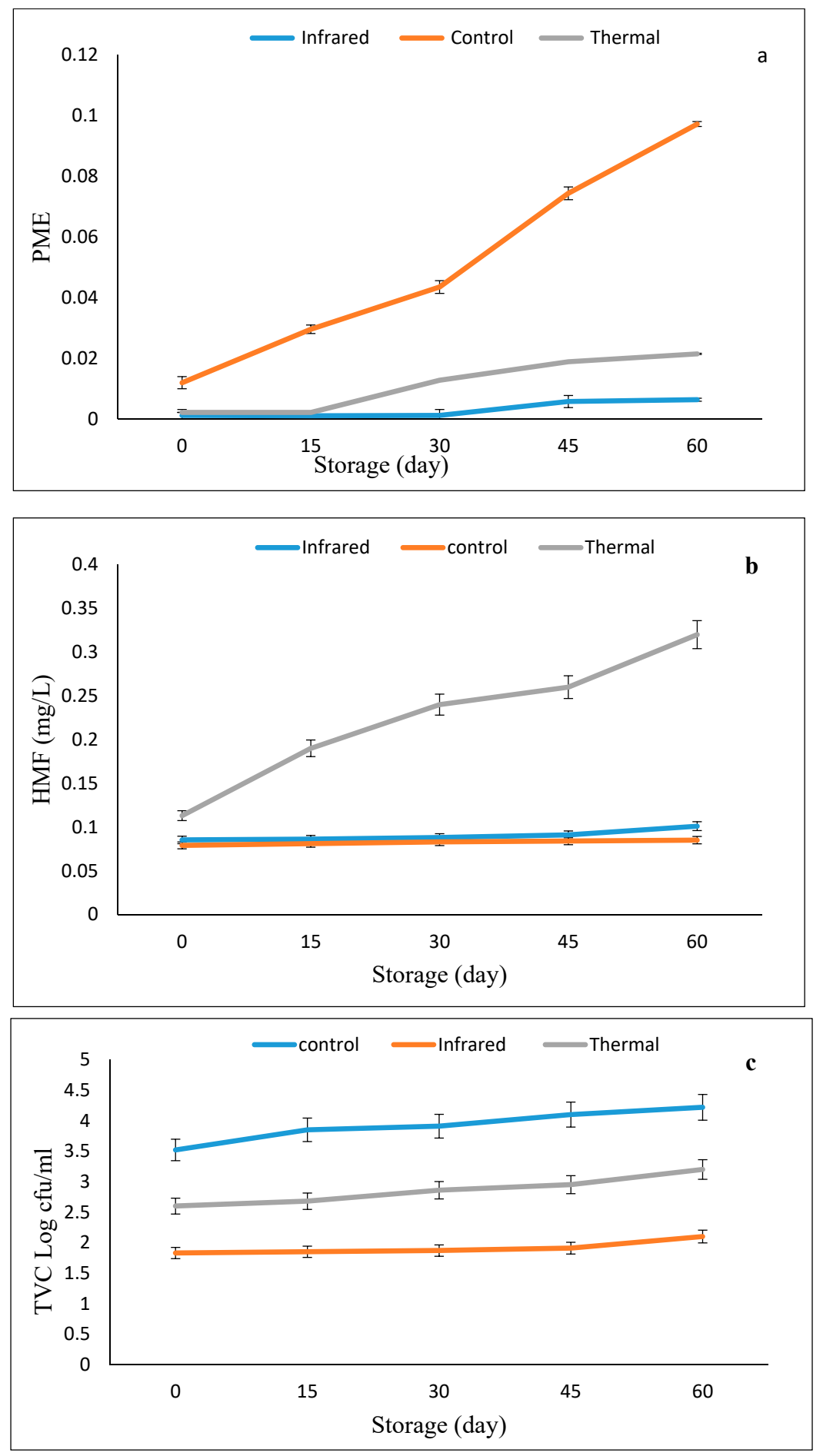

Figure 4. The (a) pectinmethylesterase activity (PME) activity, (b) hydroxymethylfurfural (HMF) content, and (c) total plate count bacteria $(\log \mathrm{cfu} / \mathrm{mL})$ of the infrared treated juice samples, the thermally treated samples (conventional), and the control sample during storage for 60 days at a temperature of $5{ }^{\circ} \mathrm{C}$. 
There was no increase in the effectiveness of the enzyme for the samples treated with infrared radiation for 30 days of storage at a temperature of $5{ }^{\circ} \mathrm{C}$, while the effectiveness of the enzyme began to increase significantly and for periods of 30 to 60 days of storage at a temperature of $5{ }^{\circ} \mathrm{C}$. Previous studies indicated the presence of heat-resistant parts that led to a decrease in the inhibition trend of the enzyme with the advancement of storage periods. The inhibition of the enzyme activity is also influenced by the heat treatment conditions such as the heating method used, time, and temperature. The results of the statistical analysis showed that the activity of the enzyme in the infrared-treated samples was significantly lower $(p<0.05)$ compared to the control sample and the thermally treated samples. In addition, the results indicated the presence of significant differences $(p<0.05)$ between the thermally treated samples and the control sample in relation to lower the enzyme activity of the thermally treated samples. This result confirms that higher temperatures cause more changes in the structure of this enzyme by breaking down the hydrogen bonds and thus reducing the activity of the enzyme [49].

\subsection{Determination of Hydroxymethylfurfural (HMF)}

Figure $4 \mathrm{~b}$ shows the hydroxymethylfurfural content of juice samples stored at $5{ }^{\circ} \mathrm{C}$ for a period of 60 days. The results obtained show that the quantity of HMF ranged between (0.0852-0.101) $\mathrm{mg} / \mathrm{L}$ for juice samples treated with infrared radiation, while the quantity of HMF ranged from (fresh) control samples and the thermally treated samples (0.079-0.085) and (0.0113-0.32) $\mathrm{mg} / \mathrm{L}$, respectively. It was noted from the results that the amount of HMF in all juice samples gradually increased during the process of cold storage at a temperature of $5{ }^{\circ} \mathrm{C}$ for 60 days. These results are in agreement with Randhawa et al. [50] who indicated that the main reason for the accumulation of HMF during storage may be due to the degradation of ascorbic acid, as was observed by other scientists in citrus juice concentrates [50,51].

The results of the statistical analysis of the sample content of HMF showed that there was a significant difference $(p<0.05)$ between the infrared-treated juice samples and the thermal juice samples during storage for 60 days at a temperature of $5{ }^{\circ} \mathrm{C}$, while the statistical analysis results showed no significant difference $(p>0.05)$ between the infrared treated juice samples and the (fresh) control sample. Moreover, the results of the statistical analysis indicated that there was a significant difference $(p<0.05)$ between the thermally treated juice samples and the (fresh) control sample. Similar results were obtained by Kadakal and Nas [52] who found a significant increase in the amount of HMF for thermally apple juice. Therefore, many researchers worked to find unconventional manufacturing methods that reduce accumulated quantities of HMF because it is considered toxic to the nervous system when it binds with proteins, which ultimately leads to muscle and visceral damage [53].

\subsection{Microbial Content of Stored Juice Samples}

Figure $4 \mathrm{c}$ shows the microbial content of juice samples stored at $5{ }^{\circ} \mathrm{C}$ for a period of 60 days. The obtained results indicate that the microbial content of the control samples was $3.85 \log \mathrm{cfu} / \mathrm{mL}$ when stored for 60 days at a temperature of $5{ }^{\circ} \mathrm{C}$. These results were consistent with Nwachukwu and Ezeigbo [54] who showed that the microbial content of fresh (unpasteurized) juice increased from $4.3 \times 10^{6}$ to $28.6 \times 10^{6} \mathrm{cfu} / \mathrm{mL}$ when stored for 14 days. The obtained results also conformed to the recommended microbiological criteria for all types of fruit juices sold in the Gulf region [55]. The results showed that the microbial content of the infrared-treated samples and the thermally treated samples also increased during the storage period. The results of the statistical analysis indicated that there were significant differences between the infrared-treated juice samples compared to the control samples and the thermally treated samples. The results of the statistical analysis showed that there was a significant difference $(p<0.05)$ between the thermally treated samples and the control sample. 


\subsection{Color Values}

\subsubsection{Lightness $\left(\mathrm{L}^{*}\right)$}

The results in the Table 1 showed that the $L^{*}$ value of lime juice was significantly $(p<0.05)$ increased from 73.60 to 83.72 when the storage period increased from 0-30 days. This may be due to the treatment of the juice with infrared rays, which led to improving the quality properties and preservation for a longer period. The results also showed that when the storage period increased from 30-60 days, the value of $L^{*}$ decreased from 83.72 to 60.80 , and this is due to an increase in the storage time, which led to physical and chemical changes in the juice. In addition, the enzymatic browning led to the formation the dark color of the juice. Reports indicate that the change in the value of $\mathrm{L}^{*}$ occurs in the color of apple juice treated with conventional heating due to the enzymatic browning that occurs during the storage periods. The $L^{*}$ value of the treated juice samples using infrared was significantly higher $(p>0.05)$ than the conventional treatment samples at all storage periods. i.e., at the 0 day of storage period, the $L^{*}$ value of the treated juice samples by infrared was 73.65 compared to the conventional (thermal) treatment samples which amounted to 65.57. The lowest value of $\mathrm{L}^{*}$ was 69.80 at the storage period of 60 days for the treated juice samples using infrared compared to the conventional treatment samples, which reached 43.72. This may be attributed to high increase in temperatures, especially in the bottom part of the tank which in contact with the electric heater. As a result, the juice was exposed to high temperature (over heating).

Table 1. The effect of storage periods on the color components of treated key lime juice using infrared, conventional heating compared to fresh (control sample).

\begin{tabular}{ccccccc}
\hline \multirow{2}{*}{$\begin{array}{c}\text { Color } \\
\text { Components }\end{array}$} & Treatments & \multicolumn{5}{c}{ Storage Period (Day) } \\
\cline { 3 - 7 } & & $\mathbf{0}$ & $\mathbf{1 5}$ & $\mathbf{3 0}$ & $\mathbf{4 5}$ & $\mathbf{6 0}$ \\
\hline & $\mathrm{IR}$ & $73.65^{\mathrm{e}} \pm 1.45$ & $78.82^{\mathrm{c}} \pm 2.11$ & $83.72^{\mathrm{b}} \pm 2.31$ & $79.21^{\mathrm{c}} \pm 1.39$ & $69.80^{\mathrm{f}} \pm 2.01$ \\
$\mathrm{~L}^{*}$ & $\mathrm{CH}$ & $65.57^{\mathrm{g}} \pm 2.05$ & $75.79^{\mathrm{d}} \pm 1.81$ & $66.86^{\mathrm{g}} \pm 1.36$ & $74.90^{\mathrm{d}} \pm 2.14$ & $43.72^{\mathrm{h}} \pm 2.31$ \\
& $\mathrm{C}$ & $75.45^{\mathrm{d}} \pm 1.78$ & $81.76^{\mathrm{b}} \pm 3.11$ & $85.29^{\mathrm{a}} \pm 3.07$ & $81.96^{\mathrm{b}} \pm 2.48$ & $74.70^{\mathrm{d}} \pm 3.11$ \\
\hline & $\mathrm{IR}$ & $14.19^{\mathrm{b}} \pm 0.57$ & $3.76^{\mathrm{j}} \pm 1.81$ & $-7.52^{\mathrm{f}} \pm 0.02$ & $-5.17^{\mathrm{h}} \pm 0.06$ & $-3.76^{\mathrm{j}} \pm 0.11$ \\
$\mathrm{a}^{*}$ & $\mathrm{CH}$ & $12.45^{\mathrm{c}} \pm 0.54$ & $6.11^{\mathrm{g}} \pm 0.16$ & $10.35^{\mathrm{d}} \pm 0.23$ & $1.881^{1} \pm 0.01$ & $2.35^{\mathrm{k}} \pm 0.10$ \\
& $\mathrm{C}$ & $16.93^{\mathrm{a}} \pm 0.23$ & $-4.70^{\mathrm{i}} \pm 0.08$ & $-8^{\mathrm{e}} \pm 0.03$ & $-13.17^{\mathrm{c}} \pm 0.12$ & $-14.58^{\mathrm{b}} \pm 0.10$ \\
\hline & $\mathrm{IR}$ & $37.52^{\mathrm{j}} \pm 1.05$ & $32.47^{\mathrm{k}} \pm 0.21$ & $74.35^{\mathrm{c}} \pm 2.31$ & $78.11^{\mathrm{a}} \pm 1.96$ & $72.47^{\mathrm{d}} \pm 0.99$ \\
$\mathrm{~b}^{*}$ & $\mathrm{CH}$ & $33.57^{\mathrm{k}} \pm 0.98$ & $65.88^{\mathrm{e}} \pm 1.08$ & $76.70^{\mathrm{b}} \pm 2.61$ & $77.64^{\mathrm{ab}} \pm 1.94$ & $61.71^{\mathrm{f}} \pm 2.01$ \\
& $\mathrm{C}$ & $39.56^{\mathrm{i}} \pm 1.11$ & $49.41^{\mathrm{h}} \pm 1.21$ & $59.78^{\mathrm{f}} \pm 1.28$ & $57.88^{\mathrm{g}} \pm 0.73$ & $74.82^{\mathrm{c}} \pm 1.01$ \\
\hline
\end{tabular}

\footnotetext{
${ }^{1}$ IR: infrared; $\mathrm{CH}$, conventional heating; $\mathrm{C}$, fresh juice (control). a-k means with same superscript letters are not significantly different
} $(p>0.05)$ within the same column

\subsubsection{Redness-Greenness $\left(\mathrm{a}^{*}\right)$}

The results in Table 1 indicated that the $a^{*}$ value of the treated juice samples using infrared was decreased significantly $(p<0.05)$ from 14.19 to 7.52 -during a storage period from $0-15$ days, respectively. While the value of $\mathrm{a}^{*}$ increased significantly $(p<0.05)$ from -7.52 to -3.76 when the storage periods increased from 30-60 days. This increase in the * value was due to the physical and chemical changes such as oxidation, in addition to the decomposition of added sugars. The results also illustrated that the $a^{*}$ value of the conventional treatment of juice samples was the highest compared to the treated juice samples by infrared and the non-treated (control) samples, with the exception of the 0-day storage period, where the differences between them were significant $(p>0.05)$. This indicates that the juice treatment by the conventional method made the Juice color was dark due to the effect of the uneven heat distribution in the juice. The highest value of $\mathrm{a}^{*}$ for the treated juice samples by infrared, the conventional treatment samples, and the non-treated (control) samples were 14.19, 12.45, and 16.93, respectively during the storage period of 0 day. The results showed that the lowest value of $a^{*}$ for the treated juice samples 
by infrared, the conventional treatment juice samples, and the non-treated juice samples (control) were 3.76, 2.35, 14.58-respectively during the storage period of 60 days.

\subsubsection{Yellowness-Blueness $\left(b^{*}\right)$}

The results in Table 1 revealed that the value of $b^{*}$ was varied with the change of storage periods, as it reached $37.52,33.57,39.56$ at using the treated juice samples by infrared, the traditional treatment samples and the non-treated samples (control), respectively during the storage period of 0 day. While during the storage period of 15 days it reached $32.47,65.88,49.41$, respectively. The results showed that the value of $a^{*}$ reached $72.47,61.71$, and 74.82 , respectively during a storage period of 60 days for the treated juice samples using infrared, the conventional and non-treated (control) samples. There were no significant differences $(p>0.05)$ between the heat treatment samples and the conventional treatment samples during the 45 days of the storage period, while significant differences $(p<0.05)$ appeared between them during the first storage period. On the other hand, there were significant differences $(p<0.05)$ between them during the first storage period. It was also noticed from the results that the value of $\mathbf{b}^{*}$ increased significantly $(p<0.05)$ when the storage period increased for all treatments. This is due to the effect of the storage period on the qualitative characteristics of the juice, as well as chemical reactions and oxidation development that may occur with the progression of the storage period, which was reflected in the color. Reports indicate that heating lemon juice with infrared rays was effective in preserving color due to reducing changes in the coloration index.

\subsection{Sensory Evaluation}

The results of the sensory evaluation are shown in Figure 5, which indicated that there was no significant difference $(p>0.05)$ between the thermally treated samples and the control sample with regard to the attributes of appearance, taste, and overall acceptability, respectively. Whereas, the results of the statistical analysis showed that there was a significant difference $(p<0.05)$ between the thermally treated samples and the control sample with respect to the aroma attribute Figure 5 . The results of the statistical analysis also showed that there are significant differences between the infrared treated samples and the thermal treatment samples and the control sample for all studied attributes. These results indicate physical, chemical, or microbial changes in the stored juice samples that were reflected on the scores of evaluation previously given. The taste panelists gave scores to the infrared-treated juice samples, which were close to the control sample directly after the production process. This result of the sensory evaluation was in agreement with Rawson et al. [56] and Alothman et al. [57] who stated that the infrared irradiation of food products may cause minimal modification in the flavor, color, nutrients, taste, and other quality attributes.

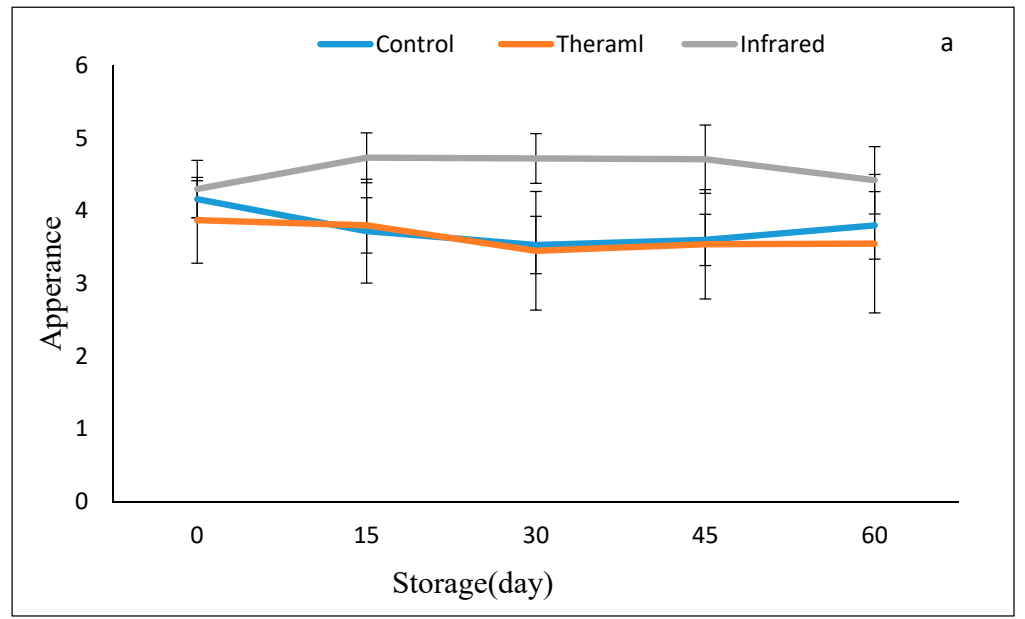

Figure 5. Cont. 

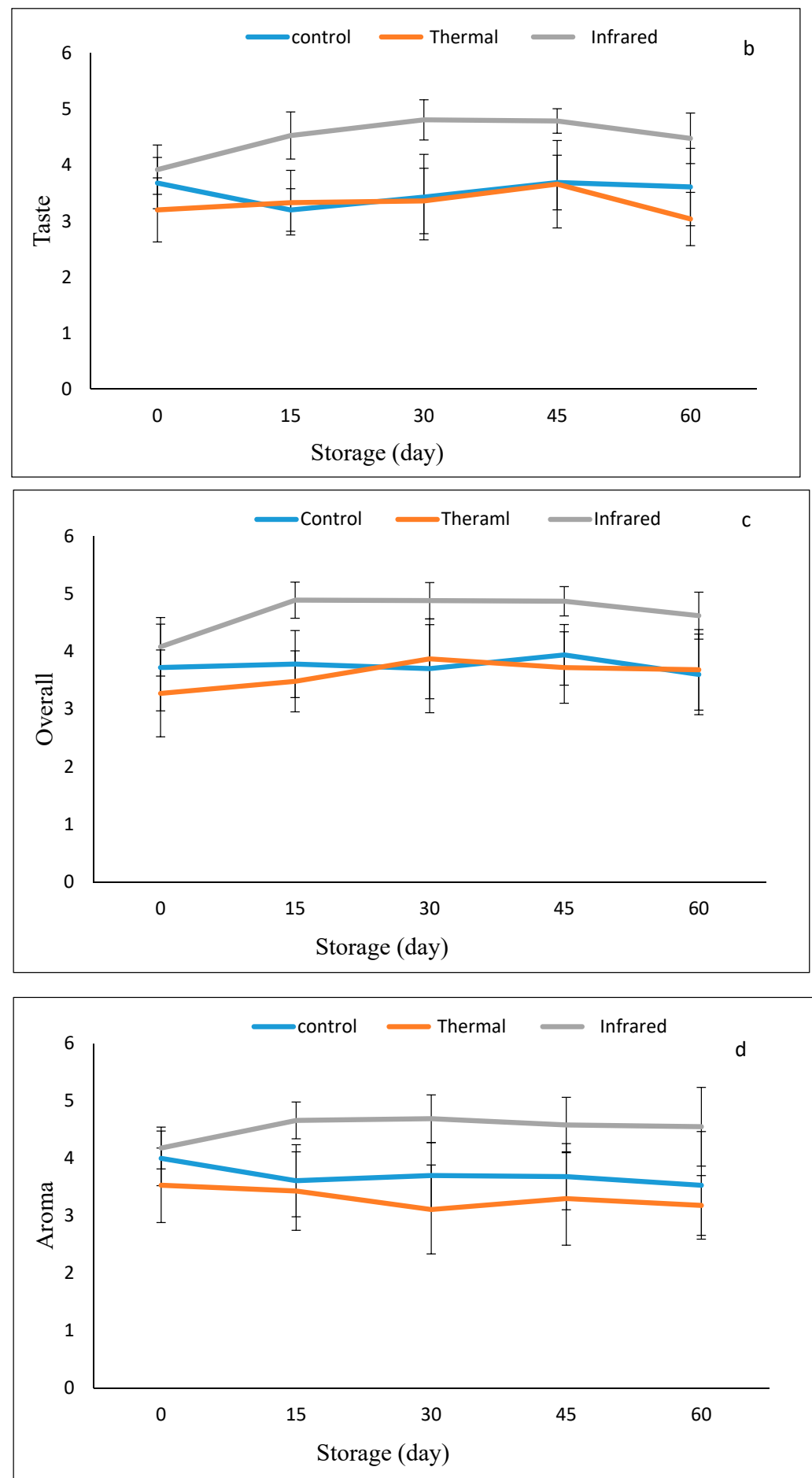

Figure 5. The effect of storage conditions on the (a) appearance attribute, (b), taste attribute, (c) overall acceptability attribute and, (d) aroma attribute of key lime juice samples stored at a temperature of $5{ }^{\circ} \mathrm{C}$ for a period of 60 days.

\section{Conclusions}

Citrus aurantifolia commonly known as key lime consists of various medicinal and nutritional qualities including alkaloids, carotenoids, coumarins, essential oils, flavonoids, phenolic acids, and triterpenoids which are extremely essential for a human body. In this study, attempts were made to preserve the native qualities of black lime juice by pasteurizing it using infrared. Initially, key lime was dried and converted into black lime and then processed to get a final product as lime juice. By the end of this study, we can 
recapitulate that infrared helps to preserve the juice in a better way than the conventional method. The entire characteristic that was studied including PMR inactivation, stability in viscosity, color, HMF index, PME inactivation reflected a positive response in the case of infrared in contrast to conventional processing. Infrared not only preserves its natural qualities but also reduces the processing time. In an overview, in the coming future, infrared can be used by the food processing industries for the preservation of juices and beverages as it helps to maintain the native attributes of a natural product.

Author Contributions: Conceptualization, A.B.A., T.G.A., and A.P.-S.; data curation, A.B.A., L.S.B., L.G., and S.N.; formal analysis, A.B.A., S.A.A., and L.S.B.; funding acquisition, L.G. and A.P.-S.; investigation, A.B.A., S.A.A., and A.P.-S.; methodology, A.B.A., A.R.S.A.-H., T.G.A., S.A.A., L.S.B., L.G., and S.N.; project administration, A.P.-S.; resources, A.P.-S.; software, A.R.S.A.-H., T.G.A., and A.P.-S.; supervision, A.P.-S.; validation, A.B.A., L.S.B., and A.P.-S.; visualization, A.R.S.A.-H., T.G.A., and L.S.B.; writing—original draft, A.B.A., A.R.S.A.-H., T.G.A., S.A.A., L.S.B., and L.G.; writingreview and editing, S.N. and A.P.-S. All authors have read and agreed to the published version of the manuscript.

Funding: This research obtained funding by the National Science and Engineering Research Council of Canada, grant number RGPIN-2018-04735 to Anubhav Pratap-Singh.

Institutional Review Board Statement: Not applicable.

Informed Consent Statement: Not applicable.

Data Availability Statement: All data is included within the manuscript.

Conflicts of Interest: The authors declare no conflict of interest.

\section{References}

1. Liu, Y.; Heying, E.; Tanumihardjo, S.A. History, Global Distribution, and Nutritional Importance of Citrus Fruits. Compr. Rev. Food Sci. Food Saf. 2012, 11, 530-545. [CrossRef]

2. Jiraungkoorskul, W.; Narang, N. Anticancer activity of key lime, Citrus aurantifolia. Pharmacogn. Rev. 2016, 10, 118-122. [CrossRef]

3. Lee, S.K.; Kader, A.A. Preharvest and postharvest factors influencing vitamin C content of horticultural crops. Postharvest Biol. Technol. 2000, 20, 207-220. [CrossRef]

4. Tiwari, B.; Muthukumarappan, K.; O’Donnell, C.; Cullen, P. Inactivation kinetics of pectin methylesterase and cloud retention in sonicated orange juice. Innov. Food Sci. Emerg. Technol. 2009, 10, 166-171. [CrossRef]

5. $\quad$ Ling, B.; Tang, J.; Kong, F.; Mitcham, E.J.; Wang, S. Kinetics of Food Quality Changes During Thermal Processing: A Review. Food Bioprocess Technol. 2014, 8, 343-358. [CrossRef]

6. Abedelmaksoud, T.G.; Mohsen, S.M.; Duedahl-Olesen, L.; Elnikeety, M.M.; Feyissa, A.H. Impact of ohmicsonication treatment on pectinmethylesterase in not-from-concentrate orange juice. J. Food Sci. Technol. 2019, 56, 3951-3956. [CrossRef]

7. Abedelmaksoud, T.G.; Mohsen, S.M.; Duedahl-Olesen, L.; Elnikeety, M.M.; Feyissa, A.H. Optimization of ohmicsonication for overall quality characteristics of NFC apple juice. J. Food Process. Preserv. 2019, 43, e14087. [CrossRef]

8. Rhim, J.W.; Nunes, R.V.; Jones, V.A.; Swartzel, K.R. Kinetics of Color Change of Grape Juice Generated using Linearly Increasing Temperature. J. Food Sci. 1989, 54, 776-777. [CrossRef]

9. Ahmed, J.; Kaur, A.; Shivhare, U. Color Degradation Kinetics of Spinach, Mustard Leaves, and Mixed Puree. J. Food Sci. 2002, 67, 1088-1091. [CrossRef]

10. Rattanathanalerk, M.; Chiewchan, N.; Srichumpoung, W. Effect of thermal processing on the quality loss of pineapple juice. J. Food Eng. 2005, 66, 259-265. [CrossRef]

11. Pratap-Singh, A.; Singh, A. Recent advances in agitation thermal processing. Curr. Opin. Food Sci. 2018, 23, 90-96. [CrossRef]

12. Pratap-Singh, A.; Singh, A. Heat transfer phenomena during thermal processing of liquid particulate mixtures-A Review. Crit. Rev Food Sci. Nutr. 2017, 57, 1350-1364. [CrossRef] [PubMed]

13. Singh, A.; Pratap-Singh, A. A Controlled Agitation Process for Improving Quality of Canned Green Beans during Agitation. Therm. Process. J Food Sci. 2016, 81, E1399-E1411. [CrossRef] [PubMed]

14. Cullen, P.; Tiwari, B.K.; Valdramidis, V.P. Status and Trends of Novel Thermal and Non-Thermal Technologies for Fluid Foods; Elsevier BV: Amsterdam, The Netherlands, 2012; pp. 1-6.

15. Rastogi, N.K. Recent Trends and Developments in Infrared Heating in Food Processing. Crit. Rev. Food Sci. Nutr. 2012, 52, 737-760. [CrossRef]

16. Nowak, D.; Lewicki, P.P. Infrared drying of apple slices. Innov. Food Sci. Emerg. Technol. 2004, 5, 353-360. [CrossRef]

17. Tan, M.; Chua, K.J.; Mujumdar, A.S.; Chou, S.K. Effect of osmotic pre-treatment and infrared radiation on drying rate and color changes during drying of potato and pineapple. Dry. Technol. 2001, 19, 2193-2207. [CrossRef] 
18. Boudhrioua, N.; Bahloul, N.; Ben Slimen, I.; Kechaou, N. Comparison on the total phenol contents and the color of fresh and infrared dried olive leaves. Ind. Crop. Prod. 2009, 29, 412-419. [CrossRef]

19. Aboud, S.A.; Altemimi, A.B.; Al-Hilphy, A.R.S.; Watson, D.G. Effect of batch infrared extraction pasteurizer (BIREP)-based processing on the quality preservation of dried lime juice. J. Food Process. Preserv. 2020, 44, 14759. [CrossRef]

20. Bhat, R.; Kamaruddin, N.S.B.C.; Min-Tze, L.; Karim, A. Sonication improves kasturi lime (Citrus microcarpa) juice quality. Ultrason. Sonochemistry 2011, 18, 1295-1300. [CrossRef]

21. Kashyap, G.; Gautam, M.D. Analysis of Vitamin C in commercial and naturals substances by iodometric titration found in Nimar and Malwaregeion. J. Sci. Res. Pharma. 2012, 1, 77-78.

22. Jafari, S.M.; Jabari, S.S.; Dehnad, D.; Shahidi, S.A. Effects of thermal processing by nanofluids on vitamin C, total phenolics and total soluble solids of tomato juice. J. Food Sci. Technol. 2017, 54, 679-686. [CrossRef]

23. Slinkard, K.; Singleton, V.L. Total phenol analysis: Automation and comparison with manual methods. Am. J. Enol. Vitic. 1977, 28, 49-55.

24. Aadil, R.M.; Zeng, X.-A.; Zhang, Z.-H.; Wang, M.-S.; Han, Z.; Jing, H.; Jabbar, S. Thermosonication: A potential technique that influences the quality of grapefruit juice. Int. J. Food Sci. Technol. 2015, 50, 1275-1282. [CrossRef]

25. Derakhshan, Z.; Ferrante, M.; Tadi, M.; Ansari, F.; Heydari, A.; Hosseini, M.S.; Conti, G.O.; Sadrabad, E.K. Antioxidant activity and total phenolic content of ethanolic extract of pomegranate peels, juice and seeds. Food Chem. Toxicol. 2018, 114, 108-111. [CrossRef] [PubMed]

26. Wiktor, A.; Mandal, R.; Singh, P.; Singh, A.; Singh, A.P. Pulsed Light treatment below a Critical Fluence $\left(3.82 \mathrm{~J} / \mathrm{cm}^{2}\right) \mathrm{minimizes}$ photo-degradation and browning of a model Phenolic (Gallic Acid) Solution. Foods 2019, 8, 380. [CrossRef] [PubMed]

27. Sethi, S.; Joshi, A.; Arora, B.; Bhowmik, A.; Sharma, R.R.; Kumar, P. Significance of FRAP, DPPH, and CUPRAC assays for antioxidant activity determination in apple fruit extracts. Eur. Food Res. Technol. 2020, 246, 591-598. [CrossRef]

28. Kimball, D.A. Citrus Processing: A complete Guide, 2nd ed.; Aspen Publishers Inc.: Gaithersburg, MD, USA, 1999 ; pp. $257-264$.

29. Cohen, E.; Birk, Y.; Mannheim, C.; Saguy, I. A Rapid Method to Monitor Quality of Apple Juice During Thermal Processing. LWT 1998, 31, 612-616. [CrossRef]

30. Keyser, M.; Múller, I.A.; Cilliers, F.P.; Nel, W.; Gouws, P.A. Ultraviolet radiation as a non-thermal treatment for the inactivation of microorganisms in fruit juice. Innov. Food Sci. Emerg. Technol. 2008, 9, 348-354. [CrossRef]

31. Benjamin, O.; Gamrasni, D. Microbial, nutritional, and organoleptic quality of pomegranate juice following high-pressure homogenization and low-temperature pasteurization. J. Food Sci. 2020, 85, 592-599. [CrossRef]

32. Yam, K.L.; Papadakis, S.E. A simple digital imaging method for measuring and analyzing color of food surfaces. J. Food Eng. 2004, 61, 137-142. [CrossRef]

33. Waghray, K.; Gulla, S.; Kumar, C.S.; Kumar, M.P.; Kumar, A.A. Sensory Quality and Acceptability of Fresh Juices. Stud. Home Community Sci. 2012, 6, 179-181. [CrossRef]

34. Ziena, H. Quality attributes of Bearss Seedless lime (Citrus latifolia Tan) juice during storage. Food Chem. 2000, 71, 167-172. [CrossRef]

35. Rodrigo, D.; Arranz, J.I. Physicochemical characteristics and quality of refrigerated Spanish orange-carrot juices and in-fluence of storage conditions. J. Food Sci. 2003, 68, 2111-2116. [CrossRef]

36. Kaddumukasa, P.P.; Imathiu, S.M.; Mathara, J.M.; Nakavuma, J.L. Influence of physicochemical parameters on storage stability: Microbiological quality of fresh unpasteurized fruit juices. Food Sci. Nutr. 2017, 5, 1098-1105. [CrossRef]

37. Mohamed, A.H.; Sulieman, A.M. Studies on pasteurized and concentrated lime juice. Zagazig J. Agric. Res. $2013,40,545-557$.

38. Torres, B.; Tiwari, B.; Patras, A.; Cullen, P.; Brunton, N.; O’Donnell, C. Stability of anthocyanins and ascorbic acid of high pressure processed blood orange juice during storage. Innov. Food Sci. Emerg. Technol. 2011, 12, 93-97. [CrossRef]

39. Doroud, M.; Daneshi, M. The Effect of Storage Temperatures on Physicochemical, Microbial and Sensory Properties of Lime Juice. Food. Eng. Res. 2019, 18, 15-52.

40. Liu, F.; Wang, Y. Effects of high hydrostatic pressure and high temperature short time on antioxidant activity, antioxidant compounds and color of mango nectars. Innova. Food Sci. Emerg. Tech. 2014, 21, 35-43. [CrossRef]

41. Castro-López, C.; Sánchez-Alejo, E.; Saucedo-Pompa, S.; Rojas, R.; Aranda-Ruiz, J.; Martínez-Avila, G. Fluctuations in phenolic content, ascorbic acid and total carotenoids and antioxidant activity of fruit beverages during storage. Heliyon 2016, 2, e00152. [CrossRef]

42. Vieira, F.N.; Lourenço, S.; Fidalgo, L.G.; Santos, S.A.O.; Silvestre, A.J.D.; Jerónimo, E.; Saraiva, J.A. Long-Term Effect on Bioactive Components and Antioxidant Activity of Thermal and High-Pressure Pasteurization of Orange Juice. Molecules 2018, $23,2706$. [CrossRef]

43. Saci, F.; Meziant, L. Effect of storage time and temperature on the health-promoting substances and antioxidant activity of two commercial fruit based-beverages. Int. J. Bioinform. Biomed. Eng. 2015, 1, 118-122.

44. Lee, S.-C.; Kim, J.-H.; Jeong, S.-M.; Kim, D.-R.; Ha, J.-U.; Nam, K.C.; Ahn, D.U. Effect of Far-Infrared Radiation on the Antioxidant Activity of Rice Hulls. J. Agric. Food Chem. 2003, 51, 4400-4403. [CrossRef]

45. Kieling, D.D.; Barbosa-Cánovas, G.V. Effects of high pressure processing on the physicochemical and microbiological pa-rameters, bioactive compounds, and antioxidant activity of a lemongrass-lime mixed beverage. J. Food Sci. Tech. 2019, 56, 409-419. [CrossRef] [PubMed]

46. Shah, N.N.A.K.; Sulaiman, A. Quality assessment of ozone-treated citrus fruit juices. Int. Food Res. J. 2019, 26, $1405-1415$. 
47. Esteve, M.; Frígola, A.; Rodrigo, C. Effect of storage period under variable conditions on the chemical and physical composition and colour of Spanish refrigerated orange juices. Food Chem. Toxicol. 2005, 43, 1413-1422. [CrossRef] [PubMed]

48. Agcam, E.; Akyıldız, A. Effects of PEF and heat pasteurization on PME activity in orange juice with regard to a new in-activation kinetic model. Food Chem. 2014, 165, 70-76. [CrossRef] [PubMed]

49. Tanaka, A.; Hoshino, E. Similarities between the thermal inactivation kinetics of Bacillus amyloliquefaciens $\alpha$-amylase in an aqueous solution of sodium dodecyl sulphate and the kinetics in the solution of anionic-phospholipid vesicles. Biotech. Appl. Biochem. 2003, 38, 175-181. [CrossRef]

50. Randhawa, M.A.; Javed, M.S.; Ahmad, Z.; Amjad, A.; Khan, A.A.; Shah, F.-U.-H.; Filza, F. Amassing of Hydroxymethylfurfural, 2-Furfural and 5-Methyl furfural in orange (Citrus reticulata) juice during storage. Food Sci. Technol. 2020, 40, 382-386. [CrossRef]

51. Burdurlu, H.S.; Koca, N.; Karadeniz, F. Degradation of vitamin C in citrus juice concentrates during storage. J. Food Eng. 2006, 74, 211-216. [CrossRef]

52. Kadakal, C.; Nas, S. Effect of heat treatment and evaporation on patulin and some other properties of apple juice. J. Sci. Food Agric. 2003, 83, 987-990. [CrossRef]

53. Li, Y.-h.; Lu, X.-y. Investigation on the origin of 5-HMF in Shengmaiyin decoction by RP-HPLC method. J. Zhejiang Uni. Sci. B 2005, 6, 1015-1021. [CrossRef] [PubMed]

54. Nwachukwu, E.; Ezeigbo, C.G. Changes in microbial population of pasteurized soursop juice treated with benzoate and lime during storage. Afr. J. Microbiol. Res. 2013, 7, 3992-3995.

55. Batool, S.; Tahir, S.; Rauf, N.; Kalsoom, R. Microbiological analysis of pasteurized and fresh fruit juice sold in Rawalpindi of Pakistan. Bangladesh J. Sci. Ind. Res. 2013, 48, 185-192. [CrossRef]

56. Rawson, A.; Patras, A.; Tiwari, B.; Noci, F.; Koutchma, T.; Brunton, N. Effect of thermal and non thermal processing technologies on the bioactive content of exotic fruits and their products: Review of recent advances. Food Res. Int. 2011, 44, 1875-1887. [CrossRef]

57. Alothman, M.; Bhat, R.; Karim, A.A. Effects of radiation processing on phytochemicals and antioxidants in plant pro-duce. Trends Food Sci. Technol. 2009, 20, 201-212. [CrossRef] 